\title{
Gamers versus the Index
}

\author{
Thomas Westin, Göran Lange \\ Department of Computer and Systems Sciences, Stockholm University, Kista, Sweden \\ Email: thomasw@dsv.su.se
}

Received 2012

\begin{abstract}
This paper presents an ethnographic study of pupils within a trial programme (P2), aimed at developing an upper secondary education for so-called 'gamers' who had 'dropped out' of school. It was done to follow up a previous trial programme (P1), since many young persons have problems with school. The main question examined here is: When we found situations where the learning worked, by means of social responsitivity, what components were active? How were meaningful affordances created? The trials may be understood from a historical perspective on orality and literacy. Print enabled words to be embedded in space as indexes (tables, lists etc) rather than in time (as orality implies). The index is practiced at the core of traditional school today, with attendance lists and schedules (controlling time and space) and schoolbooks (finalizing the word). Digital culture challenges these structures where the word is not as finalized, and literacy may include other modalities than writing. School is a culture conservative context, which fights back this transformation with more control, through the use of indexes and constraints on digital culture. As contrast, P2 replaced the schedule with full workdays. This enabled the use of commercial off-the-shelf (COTS) computer games, especially massively multiplayer online (MMO) games, as replacement for schoolbooks (not all books). The study is based on interviews with the pupils as well as daily participatory observations for two years. Further, data about attendance over two years and grades at the start and end of P2 are presented. The results show that most of the pupils returned to school, became interested in learning again and got grades. They expressed a sense of freedom, which is closely related to the voluntary aspect of playing a game. In other words, to do things for the sake of the actitivity itself, rather than some external learning goal. The paper concludes with a comparison between P2 and traditional school, based upon the study and suggests future research. A review of related research is also included.
\end{abstract}

Keywords: Games; Education; Knowledge; Learning; Culture

\section{Background}

During 2008/09, 2 to 3 \%o of pupils (aged 13-15) in Sweden had not attended school at all, for at least one month up to more than one year, without legitimate reason. In bigger cities the number was almost 6 \%. (Skolverket, 2010). Behind these figures there are many young persons; hence it is highly relevant to understand the dropout phenomena from the perspective of the pupils. The current school policy seems to focus on more attendance, testing, grades and text literacy. A recent legal case (reported by Swedish media), may be described as indirect paid work: If a pupil has too low attendance, the social support may be reduced, which mainly hurts families with low or no income. Huizinga (1971) explains the word school: "Meaning originally 'leisure' it has now acquired precisely the opposite sense of systematic work and training” (p.148). Robinson (2010) argues in a talk for the need of a paradigm shift instead of incremental improvements of the current model which traces back to the renaissance and the industrialism. This can be related to Löfberg (2000) who argues that with a culture conservative ideology both adults and children are marginalized if they deviate from the norm; i.e. the tradition and the heritage. The school system has shown an inherent inertia since it was formed in the 19th century during the pre-industrial era. In Sweden, public education was started in 1842. In that economic context it was needed that workers were able to follow instructions (as in a schoolbook) and be at a specific place (the factory/school build- ing) at the same time (the schedule). This is an obsolete model in Sweden where factories are moved abroad, and focus is put on design and research. In another talk Robinson (2006) argues that creativity, numeracy and literacy should be viewed as equally relevant. Today math and literacy has a high status in school, while the arts does not. Related to the change in the industry, this is a highly relevant point. It raises the question how education is performed. Qvarsell (2005) argues: "It is true that education is a right for all children, but education may be interpreted in different ways, not just as schooling, or as measures taken by teachers towards learners” (p.106). While Qvarsell's work focus on pre-school children, the quote may equally well be applied to older children, even adults. This paper presents an ethnographic study of a trial programme (P2), aimed at developing an upper secondary education for so-called 'gamers', who had 'dropped out' of school. Almost all of the pupils at P2 were both gamers and so-called school dropouts, not school dropouts in general. As such they may be the best informants for what works or not in general, regarding the relationship between the traditional school and the digital culture; both are contexts in which most young persons in Sweden participate. P2 was conducted during 2010-2012. It was done to follow up a previous trial programme between 2002-2006 (P1). In P1 Wiklund \& Ekenberg (2009) found that it "is clear that all 21 students in the programme perceive their situation as very positive” (p.43). Further, P1 "was seen by teachers and local school 
authorities as an experimental way of reaching students who would otherwise have a low probability of undertaking upper secondary education" (p.39). In both P1 and P2, schoolbooks (not all books) were replaced with commercial off-the-shelf (COTS) games, especially massively multiplayer online (MMO) games. Further, schedules were replaced with full workdays, and the learning environment was based upon the game worlds, not the classroom. P1 and P2 were done in two different suburbs of a big city, outside of a school building. In this paper, school is used synonymously with traditional school, which generally implies schedules, schoolbooks and physical attendance in a school building.

\section{The Index as a Perspective on School}

Ong (1982) argues that societies were originally primarily oral, and hence writing is dependent on the oral. Society today is transforming from typographic (print) culture into digital culture. This process is similar to the previous transformation from oral to written culture. Writing enabled words to be embedded in space as indexes (tables, lists, pages etc) rather than in time (as orality implies). Writing also introduced a final state of words, which is not present in oral storytelling. Print enabled words to be mass-produced. A secondary orality with e.g. massmedia and computers emerged, where the written became primary. (Ong, 1982) The index is practiced at the core of traditional school today, with attendance lists and schedules (to control time and space) and schoolbooks (finalizing the word). Digital culture challenges these structures where the word is not as finalized. In this context, literacy may include other modalities than writing (Kress, 2009). As computers are part of the secondary orality, they excel in indexing the world with e.g. search engines. Perhaps a more profound consequence of computers is that binary digits (bits) may represent virtually anything. Computers may be used to create game worlds. A world is in constant transformation; an index is merely trying to measure a selection of the world, as a snapshot at a given time. A digital index may more easily be updated than a typographic ditto, but the index is still based on a sample. Put differently, computers may be used to either 1) further the typographic culture or 2) to focus on play and develop the archaic digital culture, in Huizinga (1971) terms. It is mainly a matter of mindset of which approach is chosen. According to Ong (1982), this is also the main issue, as technology transforms our minds and culture. The authors claim that the gamer's mind, i.e. frame of reference, is within the digital culture. Many teachers' frame of reference is still within the typographic culture. With the concept of the index, it is possible to make these frames clear. This is related to the design of P2 where the index was replaced by games and digital culture. E.g. P2 replaced the schedule with full workdays. This in turn, enabled the use of commercial off-the-shelf (COTS) computer games to replace schoolbooks (but not all books). In his talk, Robinson (2010) refers to a study about divergent thinking and concludes, that children loose their ability of divergent thinking through education. Pupils are punished by the grading system due to the idea of learning goals, if they respond with divergent thinking; i.e not answering the question in the way it was meant. Asplund (1987, translated by the authors) defines social responsitivity as "human sociality and her willingness to 'respond' when 'questions' are asked of her" (p.29). Peculiarly, to be socialized he says, is equal to have your "social responsitivity strongly reduced". (ibid. p.29). To respond is according to Asplund, not a reflex as in stimulus-response; rather it is based upon an interest and motivation, and can be of any modality. School is the institution in society, which socialize pupils and the school system use the index to control and reduce social responsitivity. Grades are part of this index for control. Björnsson (1979) explains that grades emerged during the $17^{\text {th }}$ century when the nobility enjoyed privileges at state employment, over the bourgeoisie. These conditions are now gone, but the idea and practice of grades persists.

\section{Research Questions}

The main question examined here is: When we found situations where the learning worked or not, by means of social responsitivity, what components were active? How were meaningful affordances created?

\section{Related Work}

Rice (2007) identifies six different barriers to use games in education. These are mainly related to the preplanning of P2, where similar barriers were identified and budgeted for, based on experience from P1. These may be described as follows:

1) Problem: COTS games are not within the norm of education today. Outcome: This problem was predicted but not possible to handle beforehand. It resulted in an anonymous notice about P2 being submitted to the Swedish Schools Inspectorate (see Results).

2) Problem: Games made for educational purposes do not afford what the pupils' expect of games, e.g. high-end graphics. Outcome: P2 used COTS games only.

3) Problem: COTS games hardware requirements can't be supported in school. Outcome: P2 had gaming capable computers instead of schoolbooks (which made the cost approximately equal)

4) Problem: The schedule makes long gaming sessions impossible. Outcome: P2 replaced the schedule with full workdays.

5) Problem: Gee (2007) defines a "problem of content” (p.22). Outcome: This is elaborated in the analysis section.

6) Problem: Games are not aligned with the school curriculum. Outcome: This also relates to the problem of content (Gee, 2007), but is further related to the index (in the sense of control).

One perspective is that games should be viewed as valuable in themselves. (Buckingham \& Burn, 2007). This was the case in P2, where games were the base of operations. By using games, the teacher may use the 'cultural capital' (Partington, 2010) which the pupils bring to the classroom. Such capital may be game literacy. Literacy at P2 was used culturally in game worlds and creatively by creating game worlds and characters. A study of a pilot program of game design in a poor, rural area in the US (Reynolds \& Caperton, 2011), has some similarities to P2, e.g. regarding meaning-making and student engagement. They conclude: "a learning environment that many students find relevant, motivating, and in many cases fun, as well as quite difficult” (p.285). This relates closely to the results of the pupils view on P2. Another study with some resemblance to P2 used a game engine with a game editor tools (Robertson \& Good, 2005); in P2 the pupils also created game levels. A study by Kim, Park, \& Baek (2009) concludes: "a commercial off-theshelf game in game-based learning in conjunction with metacognitive strategies can be an effective learning environment 
for increasing students' performance” (p.808). P2 did not use think-aloud but observation was made of the work with creative assignments, as well as participatory observation. Charsky \& Mims (2008) argues: "Players' perceptions of the game evolve from a game to learn - to a game to play-to a game of rules - to a game of strategy" (p.40). This is related with Gee's (2007) "problem of content" (p.22); the learning goes beyond the game content itself (Gee, 2007).

Games may be viewed as Egenfeldt-Nielsen (2007) concludes: "games actually need to be tailored much closer to the actual learning content" (p.276). This tool-view is different from P2, where COTS games were the base of operations. The tool-view is also present in a paper by Hsu and Wang (2009) who argues games in school may help develop new media literacy; however, while having a focus on the classroom, games are viewed as something valuable in itself as part of new media literacy. Another paper studied a game physics engine to investigate how this could be used for physics education, which found both possibilities and constraints. (Price, 2008). While that study put focus on game technology, it was still closely related to a specific school subject, while P2 had a more thematic approach. Salen (2007) focus on the role of the game designer: "game-making is especially well-suited to encouraging meta-level reflection on the skills and processes that designer- players use in building such systems” (p.319). In other words, the process of developing games as a tool, but for learning game design, which brings it closer to P2 and the value of games in itself.

\section{Method}

This study was ethnographic with quasi-experimental interjections. The method was abductive and retroductive; the study oscillated between empirical data and hypothesis testing (mandated breakdowns) (Qvarsell, 1996). A breakdown refers to the work of Heidegger, and what is ready-to-hand versus presentat-hand (Winograd \& Flores, 1986). This study was based on four different types of data collection: 1) Individual semistructured interviews were conducted with all 18 pupils at the end of the first year. 2) Daily participatory, less structured observations with a logbook during two years. 3) Data about attendance over two years and grades at the start and end of P2. 4) Various meetings around the education with school staff, the Swedish Schools Inspectorate, the municipality and other researchers. The focus was on the pupils to tell their perceptions. A written survey or a structured interview would perhaps exclude important parts of what the pupils would say in a less structured format. A few structured questions were asked about the pupils' age and media habits as background data. The study was done with permission from the school, as some pupils were minors (below 18 years old). Interviews were recorded with smartphones. The recordings were essential in capturing the quotes included and perform coding. Memoing of observations was done in a logbook format. Quotes and memos were read closely, to find categories (such as 'freedom'). Various quotes and memos could then be organized and discussed. Tentative hypotheses could be formed and tested, e.g: freedom and creativity are active when the learning works by means of social responsitivity. Arranging and observing quasi-experiments with clay-based 3D character modelling, was a way to test this. Another tentative hypothesis was: computer gaming and game development are active when learning works, by means of so- cial responsitivity. To test this, a quasi-experiment with 3D game development was conducted for almost a year, as well as English teaching through in-game text chat and voice chat. Literature reviews was made mainly during the process, not prior to the study. Seminars with other researchers were held a few times to discuss the coding and concepts as they had emerged. One of the authors was the project manager for P2 who came to know the pupils very well by participatory observation; e.g. by playing computer games with the pupils or discussing society. This enables a deeper understanding of the interview quotes, which is elaborated in this paper. Further, the observations are used to illustrate and confirm what was found in the interviews. All data about the pupils are presented in such a way as to not reveal the identity of the pupils or to not relate opinions to a specific person.

\section{Results}

The results are presented in three sections; interviews, observations, grades and attendance. As context, a brief summary of the pupils' background is presented first.

\section{About the Pupils}

Most of the pupils lived in the suburb, and several had a socially challenged situation. All of them had significant but different problems in traditional school. They had a diverse cultural background. Almost everyone had an explicit interest for computer games. There were 20 pupils (at most), 16-19 years of age. All but one was male.

\section{Interviews about the Pupils’ Perceptions}

The pupils' perceptions of P2 in contrast to traditional school may be summarized as follows. The non-scheduled, defragmented time and space, i.e. full workdays, made it possible by design to respond to the pupils interest almost immediately. This way, the pupils were able to build a better relationship with the teacher, as communication was possible unrelated to a predefined schedule. Most of the pupils spontanously expressed a sense of freedom but also a responsibility for learning. They started to do assignments, which they would not have done in the traditional school, precisely because they did not feel controlled, but trusted. One of the pupils said: "Here they say you get a computer and you are responsible for doing your assignment. They don't nag as they did in the old school. Then you think that you must grab it with your own hands. That is why I started doing the tasks they gave me.”

The responsibility and freedom was in part expressed by the affordance of an individual path to subjects. The pupils were allowed to choose where, when and how to approach a subject, to make it meaningful. Some pupils said this leads to lifelong learning and to get different perspectives. As one pupil expressed it: "Here I may choose who I should write about and that enables me to have that knowledge for the rest of my life."

Most pupils expressed that it was fun to learn at P2, which was a major difference to their previous experience of school. They related to the relaxed atmosphere where collaboration and discussion was encouraged. An observation made by the project manager is that the atmosphere was created by the group process and socialization in the games they play. This is especially true in massively multiplayer online role-playing games (MMORPGs). The pupils didn't know each other when they started, but they 
created a strong group by playing together. The strong group creates the conditions for learning. This is confirmed in the interviews where some pupils said that there are no brawls (as in their previous schools): "It creates a peace of mind among many if you compare with the old school where there is a lot of chaos, but here it is very calm, no brawl and everyone learns from each other and a big part of that is this freedom."

A month after the interview presented above, six pupils were interviewed in-group by the Swedish Schools Inspectorate. This was done to follow-up an anonymous notice. Both the interview questions asked by the Swedish Schools Inspectorate, and the situation (in group instead of individually) were different than the first interview. Still, the pupils expressed similar opinions in both interviews, which strengthens the result. In both interviews some of the pupils expressed that P2 was the best thing that had happened to them. The freedom and own responsibility seems to be one key to why P2 worked, and why their previous schools have not worked. By being treated (almost) as responsible adults they had realized that it was up to them to learn, and nagging was not needed. In contrast they expressed a will to learn, which was a clear difference to their previous school experience. In both interviews the pupils expressed that they learn more than in their previous schools. It seems that the way they learned was another key to why P2 was perceived as a better school, e.g. the removal of the schedule and the schoolbook (but not books in general). The pupils expressed that they got good feedback from teachers and were also able to learn from their peers.

\section{Observations of Social Responsitivity}

Asplund's concept of social responsitivity (Asplund, 1987, translated by the authors), provides a perspective on ADHD, which some of the pupils had been diagnosed with. Not being able to sit still may be beneficial in a different environment, and is not exclusive for pupils with ADHD. In fact, most of the pupils could not sit still and just listen. For instance, a lesson with a teacher who spoke for more than ten minutes was observed; most of the pupils left. Some pupils didn't attend the session at all, which Asplund (1987) would call asocial responselessness. However, when creativity and discussion was in focus, the social responsitivity was very different; they attended and participated. Three examples should suffice to illustrate this.

1) The teacher in English played together with the pupils and observed how they expressed themselves, in text chat and orally via a voice-over-IP (VoIP) application. Post game play, she commented on their progress in writing and discussed with them how to improve. As she was a gamer she was accepted among the pupils.

2) The pupils were introduced to a professional and free game development environment. The pupils were able to learn how to make game levels with assistance of a university student.

3) All pupils got the opportunity to design their own 3D character, with the purpose of integrating it as a statue in a game level. Since 3D character modelling has a steep learning curve, the pupils used clay and a wire skeleton. The clay characters were $3 \mathrm{D}$-scanned by the pupils and then imported into the game engine. An artist and one of the authors assisted the pupils during two days.

They learned in a creative process, without trying to achieve external goals in the curriculum. The assignments encouraged divergent thinking and discussion. These goals were later assessed using a large matrix, where the various creative results were mapped to learning goals. This matrix was made as a spreadsheet, and a visual chart was rendered as a 'high-score list'. Related to Huizinga (1971) this made the hand-in of creative results into a contest (a game), which motivated most of the pupils to hand-in files without nagging. The assessment matrix was later used as the basis for the grading. The matrix was a necessity since P2 had to relate to the current school system and it's goals. It was a breakdown of the formative evaluation of knowledge, which was done continiously through dialogue and creative assignments.

\section{Grades and Attendance}

The data in this section were provided by one of the teachers and summarized by the authors. At the start of P2 (autumn 2010), 8/20 pupils were qualified to attend upper secondary studies. At the time when P2 started, grades in math, Swedish and English were sufficient to qualify; 12/20 pupils were not qualified in. Of these 12, 7/12 were qualified in all subjects, 4/12 had but one subject left, 1/12 had two subjects left; at the end of the second year. An important note is that during the second year of P2, the new school system in Sweden ('Gy-11') required 12 subjects to qualify. This formal change was retroactively applied to the pupils who started in the old system ('Lpf-94'); the consequence was that they had to grade in another 9 subjects to qualify.

In addition to the three qualifying subjects, all pupils had got a grade in Multimedia A, Digital media, Computer literacy, Communication and History A. 15/20 pupils had also got a grade in Virtual environments. 13/20 pupils got a grade in Multimedia B.

While P2 was run as a project outside of the school building in the suburb, attendence was approx. $75 \%$. After the move to the school building in the city, attendence was approx. 55\%. Before attending P2, most of the pupils had very low attendance. E.g. one pupil had (according to himself) previously approx. $2 \%$ attendance in secondary school.

\section{Analysis}

\section{Games and Education}

The freedom as expressed by the pupils, may be understood philosophically by the deterministic rule-based nature of games. Game rules may be tested similar to a hypothesis. While traditional school also has rules the school system doesn't encourage testing of those rules. On the contrary, pupils who do test rules in traditional school may be viewed as problems; e.g. by not following the schedule. At some points school rules are bent to avoid problems, which creates a non-deterministic context where the school can be in control. E.g. all pupils are supposed to attend every day, but it was found in one case, that attending one hour per week was enough to fulfill the rules. Finally, the fact that some of the teachers played games with the pupils may have contributed to the sense of freedom; a co-player which didn't value (or index) the achievement. Epistemologically, the focus was on communication and understanding as in a Socratic dialogue, rather than testing if external goals had been achieved.

Huizinga (1971) explains that the word 'school' originally meant 'leisure', and sophist philosophical debate was play: "It 
was pure play, catching your opponent in a net of argument" (p.147). "Only when play is a recognized cultural function - a rite, a ceremony - is it bound up with notions of obligation and duty" (p.8). The second quote captures perhaps the essence of using games in school. The moment the game-play ceases to be play and becomes obligation and duty, games transform into tools to achieve external goals. Using games in school presupposes game-play in it's own right, including the voluntary aspect of play. In other words, to do things for the sake of the activity itself rather than some external goal. A 'grasshopper' is someone who chooses to die rather than stop playing games; because then he would no longer be a grasshopper, a fate worse than dying (Suits, 2005). This may illustrate why the pupils (who were gamers) in this study returned to 'school' in P2, where playing games was not only allowed but a prerequisite to participate.

Related to Rice' fifth barrier (Rice, 2007) and the fifth problem predicted in the preplanning of P2, Gee (2007) explains that facts or concepts (often viewed as the content) is not the most important content in an academic discipline. Rather content "is generated, debated, and transformed via distinctive ways of thinking, talking, valuing, acting, and, often, writing and reading” (p.22). In a game it may be to understand a complex mission or quest, evaluate information and take action, discuss problems with other gamers etc. The game rules are learned too, of course, to be able to play the game, but that is just one part of what is being learned. This mixup is what Gee (2007) defines as the "problem of content” (p.22).

\section{Creativity and Education}

Robinson et al. (1999) defines creativity as: "Imaginative activity fashioned so as to produce outcomes that are both original and of value" (p.30). Related to Gee's (2007) reasoning about the "problem of content" (p.22): The pupils created and discussed the content they generated in the game engine or the 3D character modelling sessions. Related to Asplund's (1987) social responsitivity: The pupils participated and responded, they were interested and motivated. Related to Robinson's (2010) referral to divergent thinking: The pupils made their own interpretation of the task at hand; e.g. a 3D character could be a large dragon, a warrior with a strong pose etc. This may be called a development task; however, the school organization in which P2 was conducted, said the pupils were not ready for development tasks in e.g. English or Math. Given the results above with the advanced tasks of game development, it seems school underestimates pupils' abilities.

The pupils had what could be called ' 1337 literacy'. The word '1337' (pronounced 'leet'), is an encryption of 'elite'. It has different meanings; one is someone who excels in a game. It is also the name of this form of encryption of English, which often is used in text chats (also outside of games). It is, as Huizinga (1971) would put it, a way to demarcate the secrecy of play as something for us, but not for them. The non-gamers, the adults, the teachers are excluded from the communication.

This play with language is part of the creative process in digital culture, but the authors dare to say this is not to be found in any schoolbook of today. The written words (in a schoolbook) are finalized. Affording creativity in education takes skilled teachers who dare to leave the schoolbook and have a dialectic approach, a dialogue in which, knowledge is created by discussing various perspectives. For instance, a dialogue about language, where English as we know it is developed or trans- formed into ' 1337 '. This is merely one rather simple example of how the cultural capital (Partington, 2010) may be used in education. Related to Robinson et al. (1999) definition of creativity it affords pupils to imagine ('what if language was in this way?') and produce an original outcome about language that has value (learning english by means of their gaming experience). This was shown in the results, where the teacher played and communicated with the pupils, and the pupils got grades in this process.

In so-called profile subjects, such as multimedia and virtual worlds the creative process was part of the subject. However, the implementation of these subjects in school was still hindered by the school system. The third problem of using games in school, i.e. lack of game hardware is one aspect, but pupils also do not have administrator rights, a prerequisite to be able to experiment with and learn computer technology. Further, many schools in Sweden have outsourced the administration of computers, where all software (e.g. games) must be tested and approved with an extra cost attached. One of the schools involved in the project got their IT costs doubled with this system (in general, unrelated to the P2 project and games). These issues were worked around in P2 by having an externally funded project, which enabled buying consumer gaming PCs. This way, the pupils were able to administer their own computers, an effective way for both learning and keeping the costs down.

\section{Discussion}

The pupils' perceptions about P2 in contrast to traditional school have been presented, as well as observations of social responsitivity. It was found that the pupils preferred P2; they attended, participated and got grades in the process. To understand why P2 worked, the following matrix presents theoretical categories, which emerged from data about two social contexts for learning in the study, and relates to the other research and literature presented in this article.(Table 1)

To answer the main question, active components in situations where learning worked by means of social responsitivity included Games in it's own right, The pupil is in control, Dialectic approach and Creative assignments. While the traditional school wants to be in control, P2 gave the pupils Freedom and responsibility, similar to worklife. The Culture in P2 afforded experimentation in a sandbox context, related to the Cultural capital by using Games in it's own right. The pupil could then be in control, in the domain of games, which they knew significanlty more about than the teachers in general. Creative assignments were used for Validation of the pupils' knowledge. All these activities were performed with a Dialectic approach where different perspectives were discussed. The categories in

Table 1.

Comparing theoretical categories and social contexts for learning.

\begin{tabular}{|c|c|c|}
\hline \multirow{2}{*}{$\begin{array}{l}\text { Theoretical } \\
\text { categories }\end{array}$} & \multicolumn{2}{|c|}{ Social contexts for learning } \\
\hline & $\mathrm{P} 2$ & Traditional school \\
\hline Culture & $\begin{array}{l}\text { Games in it's own right, } \\
\text { Pupils cultural capital }\end{array}$ & $\begin{array}{l}\text { Economic utility view on } \\
\text { learning }\end{array}$ \\
\hline Freedom & $\begin{array}{l}\text { The pupil is in control, } \\
\text { Deterministic system }\end{array}$ & $\begin{array}{l}\text { The system is in control, } \\
\text { Non-deterministic system }\end{array}$ \\
\hline Learning & Dialectic approach & Schoolbook instruction \\
\hline
\end{tabular}




\begin{tabular}{clc}
\hline \multirow{2}{*}{$\begin{array}{c}\text { Theoretical } \\
\text { categories }\end{array}$} & \multicolumn{2}{c}{ Social contexts for learning } \\
\cline { 2 - 3 } & \multicolumn{1}{c}{ P2 } & Traditional school \\
\hline Validation & $\begin{array}{l}\text { Creative assignments, } \\
\text { Development tasks }\end{array}$ & Testing learning outcomes \\
\hline
\end{tabular}

the first column are related to the game world as a social context for learning. The index may be related to all items in the second column.

The active components described above were the building blocks of the environment in which the pupils were able to create meaningful affordances. A straightforward example is the defragmentation of time by replacing the schedule with full workdays, which made it possible to play MMORPGs.

Given the pupils' preferences of P2 (which validated the results from P1), it seems that P2 may be a concept for how to solve initialization to society for many pupils, in a digital culture.

The concept of P2 may be summarized as:

- Remove the schedule to integrate time, space and teacher resources into one simple structure: a full workday, which benefit dialectic feedback.

- Replace the schoolbook with meaningful affordances of the pupils' own learning path, based upon their common interest in computer games.

- Learning should be based upon collaboration and discussion (as opposed to control), between pupils and between teachers and pupils. This creates a relaxed atmosphere, where it is fun to learn.

It is vital to point out that P2 is not about creating a virtual classroom in which all pupils must be; that would be to replicate the issues with traditional school. The design of the learning must be based upon motivation and a common interest such as games. A similar concept may be used in other contexts, for other groups of pupils with other types of interests; this may be a subject for future research. Other future research would be to make a study based upon interviews with the project manager, to get more in-depth discussion of what worked and not, and more importantly, why. Further, another study would be to make a survey with questions based upon this study, to get other pupils perceptions regarding school in relationship to learning in a digital culture. Yet another study would be to make a similar survey to teacher students, regarding the need for game studies at teachers colleges. Finally, a follow-up interview with the pupils at the end of the third year is planned, to compare the situation before and after the transition into a school building.

\section{Acknowledgements}

The authors would like to thank the following persons for invaluable feedback (in alphabetic order): prof. Love Ekenberg, prof. Arvid Löfberg; prof. Birgitta Qvarsell; and Dr. Mats Wiklund, assistant supervisor.

\section{REFERENCES}

Asplund, J. (1987). Det sociala livets elementära former: Bokförlaget Korpen.

Björnsson, A. (1979). Nej till iagosamhället eller Betygen måste vi ha! Förr och nu. Tidskrift för folkets kultur, 21-28.

Buckingham, D., \& Burn, A. (2007). Game Literacy in Theory and Practice. Journal of Educational Multimedia and Hypermedia, 16(3), 323-349.
Burn, A., \& Durran, J. (2007). Media education: Literacy, learning and contemporary culture. Cambridge, England.

Charsky, D., \& Mims, C. (2008). Integrating Commercial Off-the-Shelf Video Games into School Curriculums. TechTrends, 52(5), 38-44. doi: 10.1007/s11528-008-0195-0

Egenfeldt-Nielsen, S. (2007). Third generation educational use of computer games. Journal of Educational Multimedia and Hypermedia, 16(3), 263-281.

Gee, J. P. (2007). What video games have to teach us about learning and literacy. New York: Palgrave Macmillan.

Grosin, L. (2001). Skolans legitimitet belyst genom forskningen om framgångsrika skolor. Pedagogik i barns socialisation - texter om ingripandens legitimitet, Forskningsrapporter(64).

Hsu, H.-Y., \& Wang, S. (2009). Using Gaming Literacies to Cultivate New Literacies. Paper presented at the World Conference on E-Learning in Corporate, Government, Healthcare, and Higher Education 2009, Vancouver, Canada. http://www.editlib.org/p/32637

Huizinga, J. (1971). Homo ludens: Beacon Press.

Kim, B., Park, H., \& Baek, Y. (2009). Not Just Fun, But Serious Strategies: Using Meta-Cognitive Strategies in Game-Based Learning. Computers \& Education, 52(4), 800-810.

Kress, G. (2009). Multimodality - A social semiotic approach to contemporary communication. London: Routledge.

Löfberg, K. (2000). Kultur som ideologi Utvecklingspsykologiska seminariets skriftserie, ISSN 0281-661X; 59 (pp. 26).

Ong, W. J. (1982). Muntlig och skriftlig kultur - teknologiseringen av ordet: Anthropos.

Partington, A. (2010). Game Literacy, Gaming Cultures and Media Education. English Teaching: Practice and Critique, 9(1), 73-86.

Price, C. B. (2008). The Usability of a Commercial Game Physics Engine to Develop Physics Educational Materials: An Investigation. Simulation \& Gaming, 39(3), 319-337.

Qvarsell, B. (1996). Pedagogisk etnografi för praktiken - en diskussion om förändringsfokuserad pedagogisk forskning: Pedagogiska institutionen, Stockholms universitet.

Qvarsell, B. (2001). Leka, studera, arbeta - om barns och ungas verksamheter i internationell pedagogisk belysning: Stockholms universitet: Pedagogiska institutionen.

Qvarsell, B. (2005). Early childhood culture and education for children's rights. . International Journal of Early Childhood, 37(3), 99-108.

Reynolds, R., \& Caperton, I. H. (2011). Contrasts in Student Engagement, Meaning-Making, Dislikes, and Challenges in a Discovery-Based Program of Game Design Learning. Educational Technology Research and Development, 59(2), 267-289.

Rice, J. W. (2007). New media resistance: Barriers to implementation of computer video games in the classroom. Journal of Educational Multimedia and Hypermedia, 16(3), 249-261.

Robertson, J., \& Good, J. (2005). Children's Narrative Development through Computer Game Authoring. TechTrends: Linking Research \& Practice to Improve Learning, 49(5), 43-59.

Robinson, K. (2006). Ken Robinson says schools kill creativity: TED.

Robinson, K. (2010). Changing Paradigms. London: Royal Society for the encouragement of Arts, Manufactures and Commerce, RSA.

Robinson, K., Minkin, L., Bolton, E., French, D., Fryer, L., Greenfield, S., . . . Green, L. (1999). All Our Futures: Creativity, Culture and Education.

Salen, K. (2007). Gaming literacies: A game design study in action. Journal of Educational Multimedia and Hypermedia, 16(3), 301-322.

Skolverket. (2010). Skolfrånvaro och vägen tillbaka.

Suits, B. (2005). The Grasshopper: Games, Life and Utopia: Broadview Press.

Wiklund, M., \& Ekenberg, L. (2009). Going to school in World of Warcraft. Observations from a trial programme using off-the-shelf computer games as learning tools in secondary education. Designs for learning, 2(1).

Winograd, T., \& Flores, F. (1986). Understanding Computers and Cognition. A New Foundation for Design. (24 ed.): Addison-Wesley. 